\title{
Management of Juvenile Hallux Valgus Deformity: the role of combined Hemiepiphysiodesis
}

\author{
Ming-Hung Chiang ${ }^{1}$, Ting-Ming Wang ${ }^{2,3}$, Ken N. Kuo ${ }^{2,4}$, Shier-Chieg Huang ${ }^{2}$ and Kuan-Wen Wu U $^{2,5^{*}}$ (D)
}

\begin{abstract}
Background: This study aimed to investigate the efficacy of percutaneous hemiepiphysiodesis for gradual correction of symptomatic juvenile hallux valgus (HV) deformity.

Methods: Between 2012 to 2014, 24 patients with symptomatic juvenile HV were treated by combined percutaneous medial drilling hemiepiphysiodesis of the first proximal phalanx and lateral transphyseal screw hemiepiphysiodesis of the first metatarsal at our institution. Twenty-one of 24 patients fulfilled inclusion criteria had a complete radiological and clinical follow-up of at least 2 years. Preoperative and postoperative radiographs of the feet were reviewed for measurements of hallux valgus angle (HVA), intermetatarsal angle (IMA), proximal metatarsal articular angle (PMAA), proximal phalangeal articular angle (PPAA), and metatarsal length ratio (MTLR). Clinical outcomes were assessed using the AOFAS hallux metatarsophalangeal-interphalangeal score.
\end{abstract}

Results: The study included 21 consecutive patients ( $37 \mathrm{ft}$ ) for analysis. The mean age at surgery was 12.0 years $(S D=1.3)$ and mean follow-up after surgery was 35.1 months $(S D=6.0)$. With the data available, the HV deformity improved in terms of the reduction of HVA by a mean of 4.7 degrees $(P<.001)$ and the reduction of IMA by 2.2 degrees $(P<.001)$. The PMAA and PPAA also improved significantly in the anteroposterior plane; however, the PMAA difference was insignificant in lateral plane as expected. The mean difference in the MTLR was $0.00(P=.216)$ which was indicative of no length discrepancy between first and second metatarsals. The AOFAS score increased from 68.7 to $85.2(P<.001)$. In correlation analysis, time to physeal closure was significantly correlated with the final HVA change $(r=-.611, P=.003)$.

Conclusion: Although combined hemiepiphysiodesis does not create a large degree of correction as osteotomy, yet it did improve HV deformity with adequate growth remaining in our series. It is a procedure that can be of benefit to patients with symptomatic juvenile HV from this minimal operative approach before skeletal maturity.

Level of evidence: Level IV, retrospective case series.

Keywords: Juvenile hallux valgus, Hemiepiphysiodesis, Hallux valgus angle, Intermetatarsal angle

\section{Background}

Juvenile or adolescent hallux valgus (HV), also known as bunions, is a forefoot deformity commonly seen in the skeletally immature population $[1,2]$. The deformity initially consists of lateral deviation of the great toe with the apex at the first metatarsophalangeal (MTP) joint,

\footnotetext{
* Correspondence: wukuanwen@gmail.com

2Department of Orthopaedic Surgery, National Taiwan University Hospital, No.7, Chung Shan S. Rd., Zhongzheng Dist., Taipei City 10002, Taiwan ${ }^{5}$ Institute of Biomedical Engineering, National Taiwan University, No1, Sec. 1, Jen - Ai Rd., Taipei 100, Taiwan

Full list of author information is available at the end of the article
}

but as the condition progresses it involves the entire forefoot. The etiology and natural course of this disorder have not yet been clearly understood, Coughlin et al. reported a strong maternal family history [3]. Symptoms may include painful erythematous bunion, unsatisfactory cosmesis, and difficult footwear fitting.

The management of HV deformities in skeletally immature patients remain controversial, either conservative or operative treatments. With uncertainty of halting progression in conservative management, operative intervention is often required in symptomatic skeletally immature HV

(c) The Author(s). 2019 Open Access This article is distributed under the terms of the Creative Commons Attribution 4.0 International License (http://creativecommons.org/licenses/by/4.0/), which permits unrestricted use, distribution, and reproduction in any medium, provided you give appropriate credit to the original author(s) and the source, provide a link to the Creative Commons license, and indicate if changes were made. The Creative Commons Public Domain Dedication waiver (http://creativecommons.org/publicdomain/zero/1.0/) applies to the data made available in this article, unless otherwise stated. 
$[2,4]$. However, traditional operative options, such as proximal or distal first metatarsal osteotomy, the recurrence rates have been reported at a range of $20-40 \%$ in young patients with open physis, leading to an undesirable outcome [5-7]. Accordingly, some authors advocated to postpone surgery through first metatarsal osteotomy with or without soft tissue balancing procedures until skeletal maturity [8].

The hemiepiphysiodesis in skeletally immature patients, by tethering marginal physis and creating asymmetrical physeal growth, has been used for treatment of angular deformities of the lower limbs for many years [9]. The potential advantages of hemiepiphysiodesis are less invasive, minimal scarring, and short hospital stay. Lateral hemiepiphysiodesis of the first proximal metatarsus alone has been proposed by a few previous series to correct the metatarsus varus component in juvenile HV deformity $[10,11]$. However, the smaller sample size in previous series was difficult to demonstrate the sequential angular changes and identify factors influencing the efficiency of the hemiepiphysiodesis technique after surgery.

We hypothesize that combined hemiepiphysiodesis targeting the first ray proximal phalangeal and metatarsal physis is effective in management of juvenile $\mathrm{HV}$ with adequate growth remaining. The aims are to investigate the efficacy and the complication associated with the combined procedures and the factors related to the operative outcomes.

\section{Methods}

We retrospectively reviewed the case series of all patients with juvenile HV (HV angle $>16$ degrees) who received combined hemiepiphysiodesis surgery from 2012 to 2014 at our institution. Pre-operatively, all included patients complained of pain, redness, or callosity at the bunion with failed conservative treatment, including analgesics, shoe modification or orthotics. Other requirements for inclusion were patients with a minimum of 2 years of complete radiographic and clinical follow-up. Patients with neuromuscular disease, juvenile rheumatoid arthritis and connective tissue disorders were eliminated. The medical records were reviewed for chief complaints, age at surgery, length of follow-up, the need for future foot surgeries, and complications. The study has been approved by the Research Ethics Committee of National Taiwan University Hospital (201601015RIND).

\section{Radiographic measurements}

All radiographs of the feet were taken in standard weight-bearing anterior-posterior (AP) and lateral view of foot before surgery and at 3 to 6 -month interval postoperatively until the latest follow-up. All patients had their physis closed at final follow up and the time from surgery to radiographic physeal closure was recorded. We measured the hallux valgus angle (HVA), intermetatarsal angle (IMA), proximal metatarsal articular angle (PMAA), proximal phalangeal articular angle (PPAA) (Fig. 1a \& b), the metatarsal length ratio (MTLR) and the screw position relative to physis $[10,12,13]$. The PMAA and PPAA were determined by the intersection of the bone's long axis and the line along its proximal articular surface of the first metatarsal and proximal phalanx for investigation of any alignment changes after

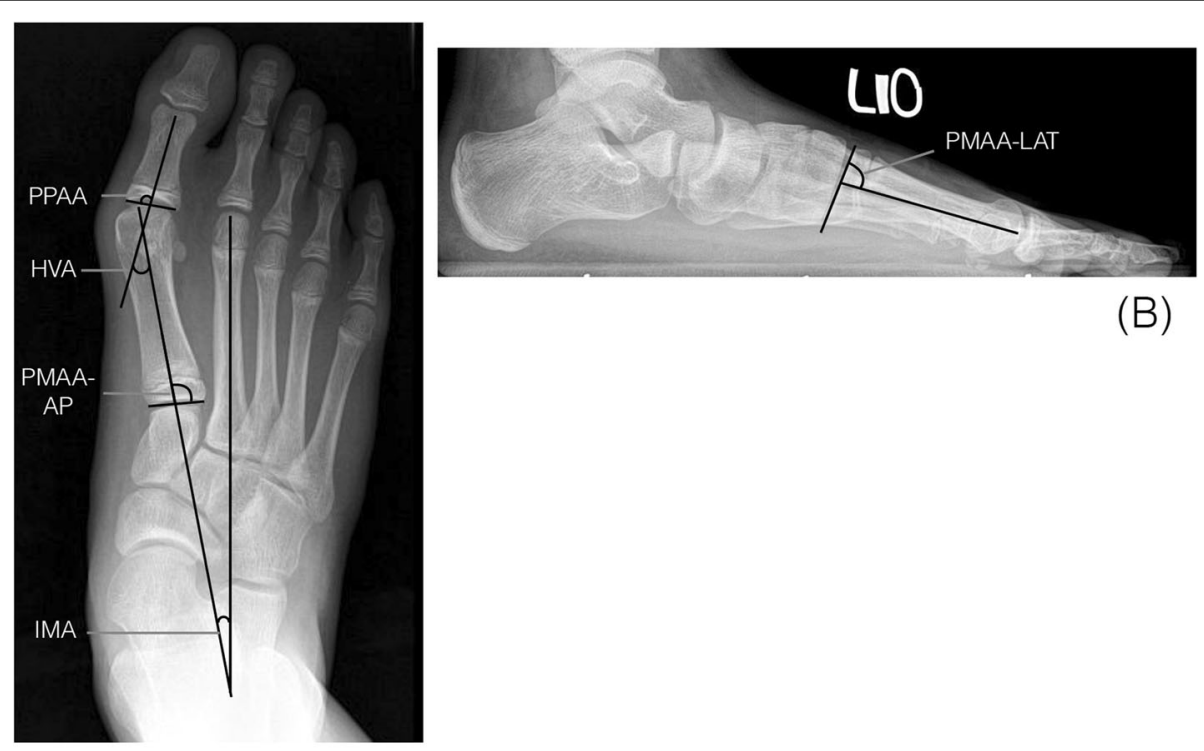

(A)

Fig. 1 Radiographic angle measurements: (a) Intermetatarsal angle (IMA), hallux valgus angle (HVA), proximal metatarsal articular angle-AP (PMAA-AP), proximal phalangeal articular angle (PPAA) (b) proximal metatarsal articular angle (PMAA-LAT) 
hemiepiphysiodesis. The distal-lateral angle and the distal-dorsal angle of the first metatarsal were defined as PMAA-AP and PMAA-LAT, respectively. The distalmedial angle of the first proximal phalanx was defined as PPAA. The MTLR was developed to assess the relative length ratio of the first and second metatarsals to assess possible shortening of the first metatarsal after lateral hemiepiphysiodesis. In order to analyze if the screw position was an influential factor, we measured the length of first metatarsal physis (B) and the distance from center of the screw that crossing the physis to lateral border of the physis (A) in the AP foot weightbearing view. The ratio of $\mathrm{A} / \mathrm{B}$ was defined as the screw position-AP (Fig. 2).

For the reliability test of radiographic measuring, Intraclass Correlation Coefficient (ICC) was used to analyze the intra-rater and inter-rater reliabilities. Regarding intrarater reliability, the measurement of above parameters was repeated at 1-week interval by a junior author using AGFA-Orthopaedic-Tools Version 2.10 (Agfa HealthCare N.V. Septestraat 27, B-2640 Mortsel, Belgium). For inter- rater reliability, two authors measured the above parameters independently using the same software.

\section{Functional assessments}

The functional assessments were evaluated with the American Orthopaedic Foot \& Ankle Society (AOFAS) hallux metatarsophalangeal-interphalangeal score which comprised of nine questions and cover three categories: Pain (40 points), function (50 points) and alignment (10 points). These are all scored together for a total of 0 to 100 points [14]. All functional and clinical outcomes were assessed in all patients preoperatively and at the final follow-up visit.

\section{Operative technique and postoperative care}

All procedures were carried out identically by the two senior authors who worked as a team. With patient on supine position under general anesthesia and fluoroscopic control, a guided wire for the cannulated screw is positioned retrograde from the medial cortex of first metatarsal mid-shaft and pointed toward the lateral and

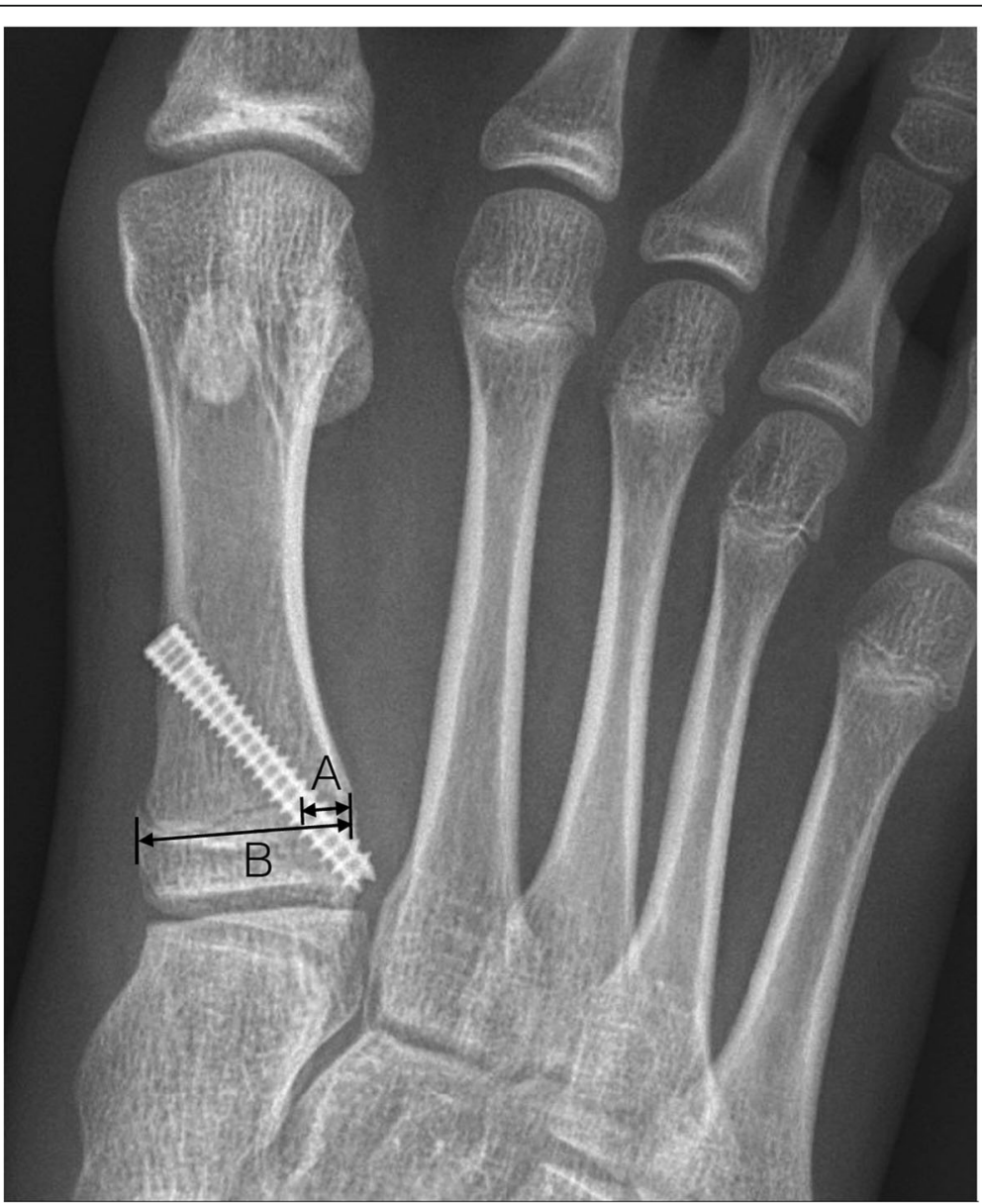

Fig. 2 Line A: from center of screw at physeal crossing to lateral border of physis parallel to line B. Line B: length of proximal physis, "A/B" represents screw position 
proximal corner of first metatarsus. The guided wire is ideally crossed through the lateral quarter of first metatarsal physis in AP view and centered of physis in lateral view (Fig. 3). After gauging the length, a cannulated drill is used to make a tunnel and then one 4.0-mm transphyseal screw is inserted (Acutrak, Acumed ${ }^{\circ}$, Oregon, USA). For medial hemiepiphysiodesis of first proximal phalanx, a guide wire is inserted through the medial quarter of first proximal phalangeal physis in dorsal-plantar direction. A stab wound is made over the pin entry and a cannulated drill is used to drill over the physis. A curved curette is then inserted into the drilled path for curettage of the surrounding physeal bone. Patients are allowed full weight-bearing ambulation immediately.

\section{Statistical analysis}

All of the parameters were checked for normality first using the Shapiro-Wilk test. Descriptive statistics were given as mean \pm standard deviation (SD). The paired sample t-test was used for comparison of the preoperative and the latest radiographic results following index surgery. Pearson's correlation test was used to analyze the relationship between the final change of HVA and preoperative demographic variables including age at surgery, time to physeal closure and radiographic parameters. All statistical analyses were performed using SPSS software, version 17.0 (SPSS, Inc., Chicago, IL, USA), and a $p$ value of $<0.05$ was defined to be statistically significant.

\section{Results}

During the period, $43 \mathrm{ft}$ of 24 patients had index procedures for symptomatic juvenile HV. Four feet from 2 patients with cerebral palsy were excluded. There was one patient who did not return for 2 years follow-up. A total of $37 \mathrm{ft}$ in 21 patients ( 9 boys and 12 girls) met our inclusion criteria for subsequent analysis. The mean age at surgery was $12.0(\mathrm{SD}=1.3)$ years. The mean age of the girls and boys at time of surgery were 11.2 $(\mathrm{SD}=0.9)$ years and 13.0 $(\mathrm{SD}=1.1)$ years respectively. Mean follow-up after surgery was $35.1(\mathrm{SD}=6.0)$ months. The mean time period from surgery to physeal closure radiographically was $15(\mathrm{SD}=4.8)$ months. The average screw position-AP was $0.25(\mathrm{SD}=0.07)$ which indicated the position of all screws crossing was consistently located at lateral quarter of the first metatarsal physis in the coronal plane. The screw position-LAT was $0.56(\mathrm{SD}=.07)$. The demographic data were summarized in Table 1.

\section{Radiographic outcomes}

The changes in the radiographic measurements of the $37 \mathrm{ft}$ after great toe proximal phalangeal and metatarsal hemiepiphysiodesis were summarized in Table 2. The mean HV angle preoperatively for all feet was 25.1 degrees and reduced to 20.4 degrees at the final follow-up. The mean correction in the HVA was 4.7 degrees with statistical significance $(P<.001)$. The HVA improved in 33 of $37 \mathrm{ft}$. Four feet in 4 patients had slight progression of HVA at final follow-up. The IMA of treated feet also significantly improved by a mean of 2.2 degrees $(P<.001)$. These feet had a mean preoperative IMA of 12.3 degrees and reduced to a mean final IMA of 10.0 degrees. The IMA improved in 32 of $37 \mathrm{ft}$. The mean correction of PMAA-AP and PPAA were 2.5 degrees $(P=.004)$ and 1.9 degrees $(P<.001)$, respectively. These feet had a mean preoperative PMAA-AP of 91.9 degrees and decreased to final of 89.4 degrees. The mean change of the metatarsal sagittal alignment (PMAALAT) was 0.2 degrees upward without statistical significance $(P=.564)$. The mean change in the MTLR was too small without statistical significance $(P=.216)$. The ICC for intra- and inter-rater reliability in all radiographic measurements was greater than 0.80 . (Table 2).

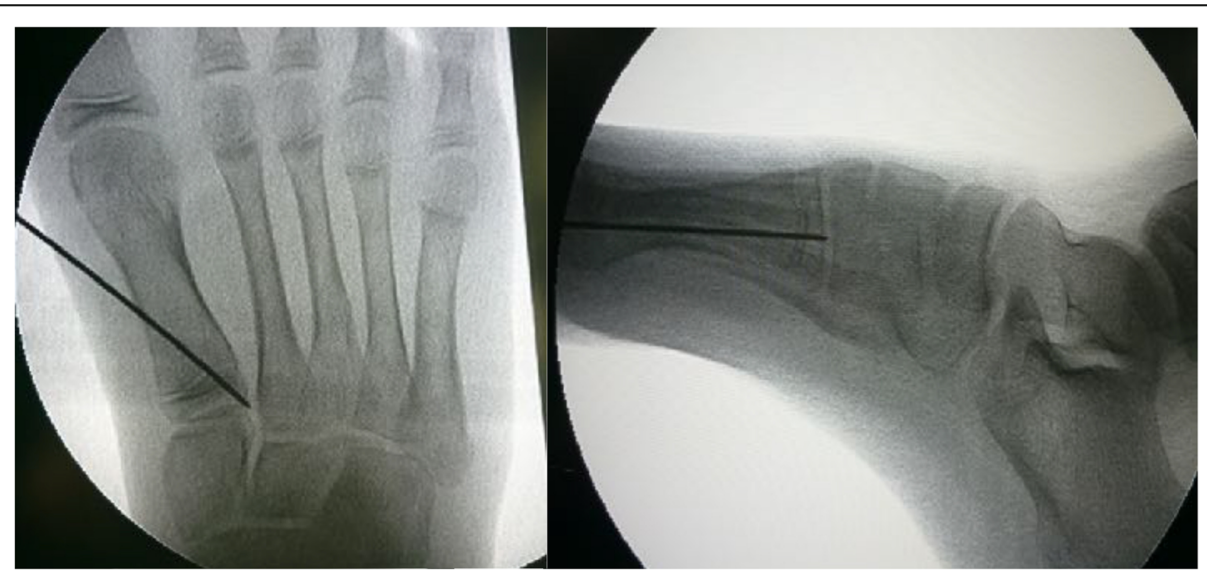

Fig. 3 Under fluoroscopic guidance, a guide wire is inserted from the medial cortex distal to the first metatarsal physis, directing to lateral third of the physis in AP view and center of the physis in lateral view 
Table 1 Demographic data

\begin{tabular}{llll}
\hline & Results & SD & Range \\
\hline No. of feet & 37 & N/A & N/A \\
Gender (M/F) & $9 / 12$ & N/A & N/A \\
Laterality (right/left) & $17 / 20$ & N/A & N/A \\
Mean age at surgery (years) & 12.0 & 1.3 & $9.5 \sim 14.5$ \\
Mean length of follow-up (months) & 35.1 & 6.0 & $26.9 \sim 51.1$ \\
Mean time to physeal closure (months) & 15 & 4.8 & $8.9 \sim 26.2$ \\
Screw position-AP & 0.25 & 0.07 & $0.11 \sim 0.40$ \\
Screw position-LAT & 0.56 & 0.07 & $0.41 \sim 0.67$ \\
\hline
\end{tabular}

Several preoperative clinical factors were analyzed with correlation test to identify potential relationships with the amount of final HVA change. The results are summarized in Table 3. Patients with longer time to physeal closure was associated with larger difference of final HVA correction $(\mathrm{r}=-.611, P=.003)$.

\section{Functional outcomes}

At the final visit, the AOFAS hallux metatarsophalangealinterphalangeal scores significantly increased from 68.7 to $85.2(P<.001)$. All patients had rapid return to school and sports activities. There was no known complication or overcorrection. No patients required revision surgery for residual HV after index procedure.

\section{Discussion}

Our results showed significant correction of HV deformity (Fig. 4). Clinical symptoms can be relieved in these pediatric population following index procedures. In 2007, Davids et al. reported significant correction of both the HVA and IMA. It was achieved in $55 \%$ of $11 \mathrm{ft}$ without worsening of either angle. They concluded that lateral hemiepiphysiodesis of the first metatarsal is a reasonable alternative for management of symptomatic or progressive juvenile $\mathrm{HV}$ [10]. The current study showed comparable results, and
Table 3 Pearson Correlation Coefficients (r) for the Relation of Final HVA Change and Pre-operative Parameters

\begin{tabular}{lll}
\hline Variables & $r$ & $P$ value \\
\hline Age & -0.133 & 0.556 \\
Time to physeal closure & -0.611 & $0.003^{*}$ \\
Pre-OP HVA & -0.005 & 0.977 \\
Pre-OP IMA & 0.214 & 0.204 \\
Pre-OP PPAA & -0.312 & 0.060 \\
Pre-OP PMAA-AP & 0.271 & 0.104 \\
Pre-OP MTLR & 0.266 & 0.112 \\
\hline${ }^{*}<<0.05$ & &
\end{tabular}

higher percentage of patients had significant HVA correction $(89 \%, 33$ of 37$)$.

Treatment for juvenile HV has always been a challenging problem because of its unclear etiology, pathophysiology, and growing process. Operative correction of symptomatic HV deformities is often recommended once conservative treatment has failed. Unlike the adult population, the high recurrence rate is still a major concern in the treatment of skeletally immature $\mathrm{HV}$ by conventional metatarsal osteotomy techniques $[5,6,15]$. An open metatarsal physis has been believed as a predisposing factor to the recurrence risk. Despite innovated technique and methods of fixation have improved the operative outcomes and lowered recurrence rate to $8 \%$ based on a recent systematic review article, most of the series included were focused on the adolescent rather than juvenile population $[2,15]$. Temporary maintenance with orthotics and postponing surgery until mid- to late teens is usually preferred for skeletally immature HV. However, study of the natural history showed juvenile HVA might increase by 0.8 degrees per year [16]. Our study revealed a reversed trend of the HVA progression. (Table 4).

Most of conventional operative modalities neglect the potential of manipulating the physeal growth of the first metatarsal and proximal phalanx to stop deformity progression and allow gradual correction of skeletal deformity. A small number of studies have suggested the lateral

Table 2 Summary of Radiographic Measurements and Functional Assessments

\begin{tabular}{|c|c|c|c|c|c|c|c|c|c|c|}
\hline & \multicolumn{2}{|l|}{ Pre-OP } & \multicolumn{2}{|c|}{ Post-OP } & \multicolumn{4}{|c|}{ Difference } & \multirow{2}{*}{$\begin{array}{l}\text { Intra- } \\
\text { rater } \\
\text { reliability }\end{array}$} & \multirow{2}{*}{$\begin{array}{l}\text { Inter- } \\
\text { rater } \\
\text { reliability }\end{array}$} \\
\hline & Mean & SD & Mean & SD & Mean & $95 \% \mathrm{Cl}$ & SD & $P$ value & & \\
\hline HVA & 25.1 & 4.8 & 20.4 & 6.3 & -4.7 & $-6.1 \sim-3.3$ & 4.1 & $<0.001^{*}$ & 0.969 & 0.916 \\
\hline IMA & 12.3 & 2.4 & 10.0 & 2.7 & -2.2 & $-2.9 \sim-1.6$ & 2.0 & $<0.001^{*}$ & 0.914 & 0.876 \\
\hline PMAA-AP & 91.9 & 5.0 & 89.4 & 6.6 & -2.5 & $-4.1 \sim-0.9$ & 4.9 & $0.004^{*}$ & 0.941 & 0.917 \\
\hline PPAA & 97.4 & 2.7 & 95.4 & 2.8 & -1.9 & $-2.7 \sim-1.2$ & 2.2 & $<0.001^{*}$ & 0.897 & 0.813 \\
\hline PMAA-LAT & 86.0 & 1.9 & 85.8 & 1.8 & -0.2 & $-0.7 \sim 0.4$ & 1.6 & 0.564 & 0.816 & 0.859 \\
\hline MTLR & 0.83 & 0.03 & 0.83 & 0.04 & 0.00 & $-0.01 \sim 0.01$ & 0.02 & 0.216 & 0.922 & 0.940 \\
\hline AOFAS & 68.7 & 10.1 & 85.2 & 12.3 & 16.5 & $13.9 \sim 19.1$ & 7.8 & $<0.001$ & - & - \\
\hline
\end{tabular}

HVA hallux valgus angle, IMA intermetatarsal angle, PMAA-AP proximal metatarsal articular angle in AP view, PPAA proximal phalangeal articular angle, PMAA-LAT proximal metatarsal articular angle in lateral view, MTLR $1 \mathrm{st} / 2$ nd metatarsal length ratio, $C /$ confidence interval. ${ }^{*} P<0.05$ in Paired Samples T-test. ${ }^{\mathrm{C}}$ Correlation Coefficient. SD: Standard deviation 


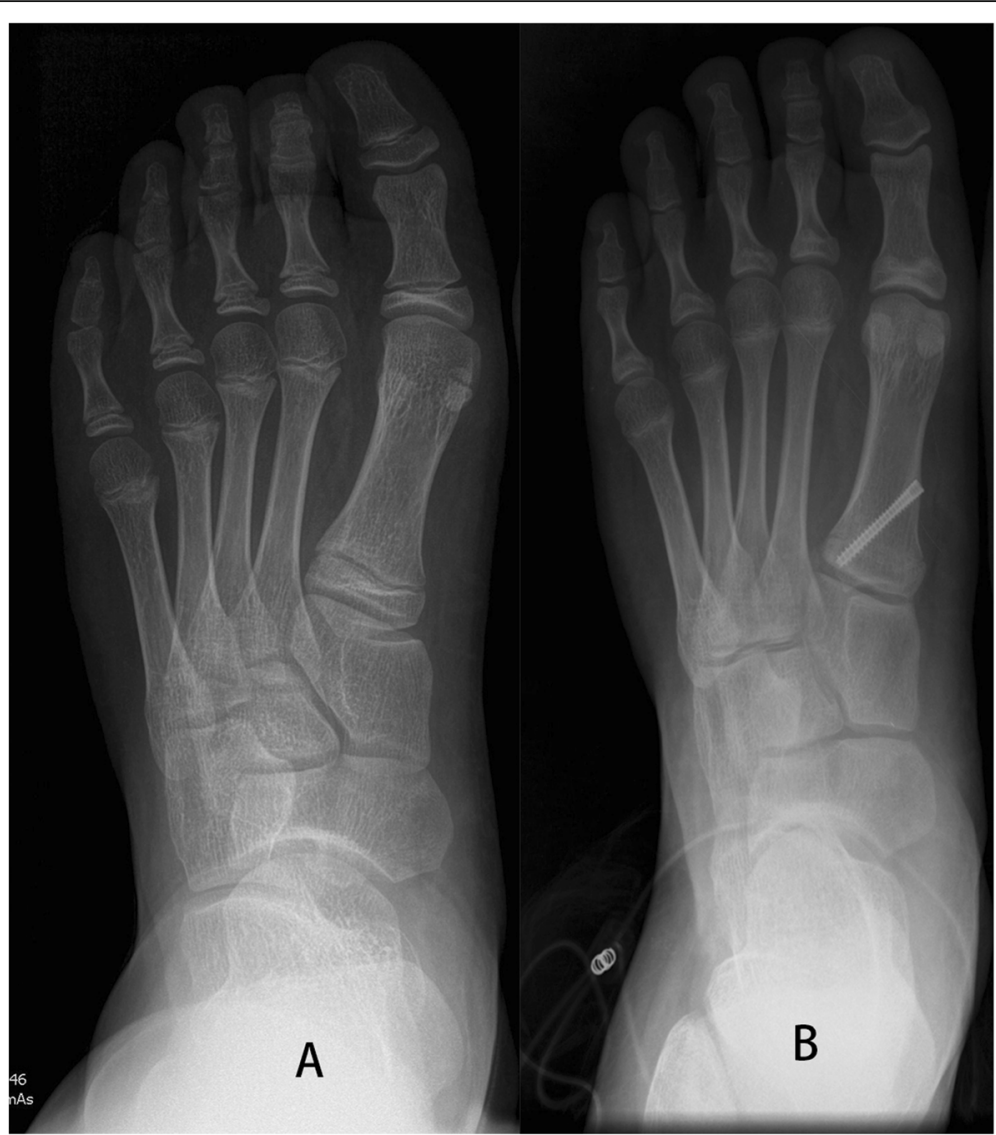

Fig. 4 a The case example shows the initial HVA was 25.5 degrees, and IMA was 8.5 degrees at age of twelve. b Two years and 2 months after the operation, the HVA improved to 14.6 degrees, and IMA improved to 4.7 degrees

hemiepiphysiodesis of the first metatarsal is a reasonable alternative for the symptomatic or progressive juvenile HV $[10,11]$. However, prior techniques used for lateral hemiepiphysiodesis, either curettage or stapling, could not compare with percutaneous manner in simplicity and effectiveness.

A temporary epiphysiodesis using transphyseal screw, described by Metaizeau et al. [9] and then by Khoury et al. [17], is a true percutaneous technique and effective for limb length discrepancy and angular deformities

Table 4 Comparison of Current Study and Natural Course Study (Sung et al)

\begin{tabular}{lll}
\hline & Current Study & Sung et al \\
\hline Age at first visit (years) & 12.0 & 10.2 \\
HVA at first visit & 25.1 & 18.4 \\
IMA at first visit & 12.3 & 10.1 \\
Follow-up duration (years) & 2.9 & 2.8 \\
Progression rate of HVA (degrees/year) & -1.8 & 0.8 \\
Progression rate of IMA (degrees/year) & -0.8 & 0.0 \\
\hline
\end{tabular}

HVA hallux valgus angle, IMA intermetatarsal angle Negative value in progression rate indicative of improvement correction. In our strategy, a simple stab wound each can achieve hemiepiphysiodesis in both locations, provides immediate ambulation. The transphyseal screw technique also carries a theoretical advantage of reversibility compares to traditional physeal ablation technique [17].

Although the potential for correction is not as powerful as osteotomies based on prior studies, ranging from 7.3 degrees to 21.54 degrees change in HVA, and 0.87 to 9.25 degrees change in IMA [7, 15, 18-24], osteotomy procedures also carry higher complication rates $(22.9 \%)$, such as metatarsal shortening, first metatarsal-phalangeal (MTP) joint stiffness, and recurrent HV deformity [2]. Shortening or dorsiflexion of the first ray are common complications of HV osteotomy and may result in transfer metatarsalgia [25]. In the other way, our result didn't show significant change in metatarsal length ratio (MTLR) or sagittal alignment (PMAA-LAT).

Despite of hemiepiphysiodesis, the deformity may still progress for reasons including timing of surgery, quality of surgery, and underlying cause of deformity. Four feet in 4 patients in this study had slight progression of HVA. One foot might have the screw placed too laterally (a screw position AP of 0.12); therefore, less threads can 
purchase epiphysis. The failure of other $3 \mathrm{ft}$ might be attributed to late timing for surgery (less than 9 months before permanent physeal closure). From our analysis, time to physeal closure was correlated with the final HVA change. Although there is still no consensus on the optimal timing of metatarsal hemiepiphysiodesis, previous studies suggested that adequate growth remaining to achieve significant correction by hemiepiphysiodesis is up to 10 years for girls and up to 12 years for boys [26]. The mean age at surgery in our series was 11.2 years for girls and 13.0 years for boys which were relative older than prior studies. According to the growth chart by Nelson [26], the estimated growth of the first metatarsal is only $8 \sim 10 \%$ remaining in our study group. At this late stage of foot growth, it is unlikely to cause significant shortening of the first metatarsal by our procedures, but the power of angular correction may not be as adequate. Consequently, proximal phalangeal hemiepiphysiodesis was added as a supplementary procedure to augment $\mathrm{HV}$ correction. For optimum results, this surgery may be performed a few months earlier than the operative age in current series. The authors agreed with Davids et al. [10] that the best timing of the index procedure should be performed with 2 or more years of growth remaining.

This study had two limitations. First, this is a retrospective case series study with limited sample size. Second, this study didn't directly compare with untreated patients with juvenile HV. In spite of this, most of the patients in this study had improvement in HVA and IMA, which were better than those following their natural history [16].

\section{Conclusions}

With adequate growth remaining, the combined metatarsal and proximal phalangeal hemiepiphysiodesis is a simple and effective procedure for juvenile $\mathrm{HV}$ patients with minimal approach. Although combined hemiepiphysiodesis does not create a large degree of correction as osteotomy, the percutaneous procedures greatly reduce the postoperative disability with immediate weight-bearing. The metatarsal length ratio and the sagittal alignment of the first metatarsal were retained. Longer follow-up is needed to observe possible recurrence of the deformity. In the future, a head-to-head comparison with non-surgical cases would help to draw firm conclusions.

\section{Abbreviations}

HVA: hallux valgus angle; IMA: intermetatarsal angle; MTLR: metatarsal length ratio; PMAA: proximal metatarsal articular angle; PPAA: proximal phalangeal articular angle; SD: standard deviation

\section{Acknowledgements}

We thank the staff of Biotechnology R\&D Center, National Taiwan University Hospital, Hsin-Chu Branch for their assistance in statistical analysis.

\section{Authors' contributions}

TMW and KNK formed the conceptual idea. MHC and KWW collected the cases and analysed the materials. MHC did the statistical work. MHC and KWW authored the original draft. TMW, KNK, and SCH provided critical revision of the manuscript and supervised the research. All authors have read and approved the manuscript, including the case example.

\section{Funding \\ The authors declare no funding, financial support, or potential source of a conflict of interest related to this work.}

\section{Availability of data and materials}

The datasets used and/or analyzed during the current study are available from the corresponding author on reasonable request.

\section{Ethics approval and consent to participate}

Each author certifies that his institution has approved the human protocol for this investigation, that all investigations were conducted in conformity with ethical principles of research, and that informed consent was obtained. The Research Ethics Committee of the National Taiwan University Hospital approved this study (201601015RIND).

\section{Consent for publication}

Not applicable

\section{Competing interests}

The authors declare that they have no competing interests.

\section{Author details}

'Department of Orthopaedic Surgery, National Taiwan University Hospital Hsin-Chu Branch, No.25, Lane 442, Sec.1, Jingguo Rd., Hsinchu City 300, Taiwan. ${ }^{2}$ Department of Orthopaedic Surgery, National Taiwan University Hospital, No.7, Chung Shan S. Rd., Zhongzheng Dist., Taipei City 10002,

Taiwan. ${ }^{3}$ Department of Orthopaedic Surgery, School of Medicine, National Taiwan University, No1, Sec. 1, Jen-Ai Rd., Taipei City 10051, Taiwan.

${ }^{4}$ Cochrane Taiwan, Taipei Medical University, No. 250 Wu-Xing Street, Taipe City 11031, Taiwan. ${ }^{5}$ Institute of Biomedical Engineering, National Taiwan University, No1, Sec. 1, Jen - Ai Rd., Taipei 100, Taiwan.

Received: 10 January 2019 Accepted: 9 October 2019

Published online: 25 October 2019

\section{References}

1. Geissele AE, Stanton RP. Surgical treatment of adolescent hallux valgus. J Pediatr Orthop. 1990;10(5):642-8.

2. Harb $Z$, Kokkinakis $M$, Ismail $H$, Spence $G$. Adolescent hallux valgus: a systematic review of outcomes following surgery. J Child Orthop. 2015; 9(2):105-12.

3. Coughlin MJ. Roger a. Mann award. Juvenile hallux valgus: etiology and treatment. Foot Ankle Int. 1995;16(11):682-97.

4. Kilmartin TE, Barrington RL, Wallace WA. A controlled prospective trial of a foot orthosis for juvenile hallux valgus. The Journal of bone and joint surgery British volume. 1994;76(2):210-4.

5. Scranton PE Jr, Zuckerman JD. Bunion surgery in adolescents: results of surgical treatment. J Pediatr Orthop. 1984:4(1):39-43.

6. Ball J, Sullivan JA. Treatment of the juvenile bunion by Mitchell osteotomy. Orthopedics. 1985:8(10):1249-52

7. George HL, Casaletto J, Unnikrishnan PN, Shivratri D, James LA, Bass A, Bruce CE. Outcome of the scarf osteotomy in adolescent hallux valgus. J Child Orthop. 2009;3(3):185-90.

8. Myerson M: Hallux valgus. In: Foot and ankle disorders. edn. Philadelphia: Saunders; 2000: 213-288

9. Metaizeau JP, Wong-Chung J, Bertrand H, Pasquier P. Percutaneous epiphysiodesis using transphyseal screws (PETS). J Pediatr Orthop. 1998; 18(3):363-9.

10. Davids JR, McBrayer D, Blackhurst DW. Juvenile hallux valgus deformity: surgical management by lateral hemiepiphyseodesis of the great toe metatarsal. J Pediatr Orthop. 2007:27(7):826-30.

11. Seiberg M, Green R, Green D. Epiphysiodesis in juvenile hallux abducto valgus. A preliminary retrospective study. J Am Podiatr Med Assoc. 1994 84(5):225-36. 
12. Coughlin MJ, Saltzman CL, Nunley JA 2nd. Angular measurements in the evaluation of hallux valgus deformities: a report of the ad hoc committee of the American Orthopaedic Foot \& Ankle Society on angular measurements. Foot Ankle Int. 2002:23(1):68-74.

13. Coughlin MJ, Saltzman CL, Mann RA: Mann's surgery of the foot and ankle E-book: expert consult - online: Elsevier health sciences; 2013.

14. Kitaoka HB, Alexander IJ, Adelaar RS, Nunley JA, Myerson MS, Sanders M. Clinical rating systems for the ankle-hindfoot, midfoot, hallux, and lesser toes. Foot Ankle Int. 1994;15(7):349-53.

15. Johnson AE, Georgopoulos G, Erickson MA, Eilert R. Treatment of adolescent hallux valgus with the first metatarsal double osteotomy: the Denver experience. J Pediatr Orthop. 2004;24(4):358-62.

16. Sung KH, Kwon SS, Park MS, Lee KM, Ahn J, Lee SY. Natural progression of radiographic indices in juvenile hallux valgus deformity. Foot Ankle Surg. 2019;25(3):378-82.

17. Khoury JG, Tavares JO, McConnell S, Zeiders G, Sanders JO. Results of screw epiphysiodesis for the treatment of limb length discrepancy and angular deformity. J Pediatr Orthop. 2007;27(6):623-8.

18. Farrar NG, Duncan N, Ahmed N, Rajan RA. Scarf osteotomy in the management of symptomatic adolescent hallux valgus. J Child Orthop. 2012;6(2):153-7.

19. Gicquel T, Fraisse B, Marleix S, Chapuis M, Violas P. Percutaneous hallux valgus surgery in children: short-term outcomes of 33 cases. Orthopaedics \& traumatology, surgery \& research : OTSR. 2013;99(4):433-9.

20. John S, Weil L Jr, Weil LS Sr, Chase K. Scarf osteotomy for the correction of adolescent hallux valgus. Foot \& ankle specialist. 2010;3(1):10-4

21. Andreacchio A, Origo C, Rocca G. Early results of the modified SimmondsMenelaus procedure for adolescent hallux valgus. J Pediatr Orthop. 2002; 22(3):375-9.

22. Okuda R, Yasuda T, Jotoku T, Shima H. Proximal abduction-supination osteotomy of the first metatarsal for adolescent hallux valgus: a preliminary report. Journal of orthopaedic science : official journal of the Japanese Orthopaedic Association. 2013;18(3):419-25.

23. Petratos DV, Anastasopoulos JN, Plakogiannis CV, Matsinos GS. Correction of adolescent hallux valgus by proximal crescentic osteotomy of the first metatarsal. Acta Orthop Belg. 2008;74(4):496-502.

24. Kraus T, Singer G, Svehlik M, Kaltenbach J, Eberl R, Linhart W. Long-term outcome of chevron-osteotomy in juvenile hallux valgus. Acta Orthop Belg. 2013;79(5):552-8.

25. Stokes IA, Hutton WC, Stott JR, Lowe LW. Forces under the hallux valgus foot before and after surgery. Clin Orthop Relat Res. 1979;142:64-72.

26. Nelson JP. Mechanical arrestment of bone growth for the correction of pedal deformities. The Journal of foot surgery. 1981;20(1):14-6.

\section{Publisher's Note}

Springer Nature remains neutral with regard to jurisdictional claims in published maps and institutional affiliations.

Ready to submit your research? Choose BMC and benefit from:

- fast, convenient online submission

- thorough peer review by experienced researchers in your field

- rapid publication on acceptance

- support for research data, including large and complex data types

- gold Open Access which fosters wider collaboration and increased citations

- maximum visibility for your research: over $100 \mathrm{M}$ website views per year

At $\mathrm{BMC}$, research is always in progress.

Learn more biomedcentral.com/submissions 